\title{
Apuntes respecto al carácter de norma común de la Ley del Procedimiento Administrativo General en los procedimientos administrativos sancionadores en materia de protección al consumidor
}

\author{
Daniela Supo Calderón* \\ Ana del Rosario Gamero**
}

\begin{abstract}
Resumen. - A partir de las modificaciones establecidas por el Decreto Legislativo 1272 se adoptó un cambio sustancial en relación a la aplicación de la LPAG en los procedimientos administrativos sancionadores, estableciéndose que las condiciones plasmadas en la referida norma pasen de ser supletorias a ser condiciones mínimas que deben regir en todos los referidos procedimientos. El presente artículo tiene como objetivo analizar cómo se han venido aplicando las modificaciones del Decreto Legislativo referido en el marco de los procedimientos de protección al consumidor tramitados ante el INDECOPI.
\end{abstract}

\begin{abstract}
As per the modifications set forth by Legislative Decree 1272, an important change was adopted regarding the application of the General Administrative Procedure Law (LPAG, for its acronym in Spanish) in the sanctioning administrative proceedings, as the conditions set forth in the LPAG changed from being supplementary to being minimum conditions which must be complied in all proceedings. This article aims to analyse how the modifications to the Legislative Decree have been applied according to the Consumer Protection framework before INDECOPI.
\end{abstract}

Palabras claves. - Decreto Legislativo 1272 - Procedimientos Administrativos Sancionadores - Protección al Consumidor - Ley de Procedimiento Administrativo General - INDECOPI

Keywords. - Decree Law 1272 - Sanctioning Administrative Procedures - Consumer Protection - General Administrative Procedure Law - INDECOPI

* Abogada por la Universidad de Lima. Actualmente se desempeña como Abogada Asociada del área de Propiedad Intelectual en Rodrigo, Elías \& Medrano Abogados.

** Abogada por la Pontificia Universidad Católica del Perú, con Segunda Especialidad en Protección al Consumidor por la misma Universidad. Actualmente se desempeña como Analista Legal de la Comisión de Protección al Consumidor No. 3 del INDECOPI. 


\section{Introducción}

A tres años de la entrada en vigencia del Decreto Legislativo 12721 (publicado en el diario oficial El Peruano el 21 de diciembre de 2016), mediante el cual fueron modificadas diversas disposiciones de la Ley del Procedimiento Administrativo General (en adelante, LPAG), el propósito de las autoras es realizar un breve diagnóstico de la forma en la que algunas modificaciones se han venido aplicando en los procedimientos administrativos sancionadores en materia de protección al consumidor tramitados ante el Instituto Nacional de Defensa de la Competencia y de la Protección de la Propiedad Intelectual (en adelante, Indecopi).

Para ello, es necesario partir estableciendo que una de las modificaciones más sustanciales que trajo consigo el Decreto Legislativo 1272 fue el cambio de naturaleza de la LPAG, la cual se convirtió en una norma de aplicación común. En efecto, antes de la entrada en vigencia del Decreto Legislativo 1272, la LPAG se aplicaba en forma obligatoria únicamente cuando la norma especial no establecía regulación alguna, es decir, su aplicación era supletoria. Esta condición varía de manera sustancial con las modificaciones introducidas mediante el referido Decreto Legislativo, las cuales establecen -en pocas palabras- que las disposiciones de la LPAG dejen de ser supletorias para ser de aplicación imperativa en todos los procedimientos especiales, estableciéndose así condiciones mínimas comunes que deben ser respetadas en todos los procedimientos administrativos en general.

Resulta claro que debido a la especialidad de cada procedimiento en específico es necesario contar con una regulación especial (motivo por el cual en el ordenamiento jurídico peruano existe una diversidad de normas que regulan los procedimientos sancionadores especiales). No obstante, la condición de especialidad no es óbice para excluir la necesidad de también contar con determinadas condiciones y garantías mínimas que regulen los procedimientos administrativos sancionadores. Se trata de establecer pautas comunes que sirvan como "piso" para la tramitación de los procedimientos administrativos sancionadores.

Ahora bien, la finalidad del presente artículo es realizar un breve análisis en relación a cómo viene siendo aplicado el carácter común de la LPAG en los procedimientos administrativos sancionadores de protección al consumidor, regulados a través de la Ley 29571, Código de Protección y Defensa del Consumidor (en adelante, Código). En ese sentido, de una revisión de la jurisprudencia emitida con posterioridad a la entrada en vigencia del Decreto Legislativo 1272 por los diferentes Órganos Resolutivos en materia de protección

1 Cabe indicar que, si bien las instituciones a tratarse en el presente artículo fueron introducidas a la norma mediante el Decreto Legislativo 1272 (y posteriormente plasmadas en el Texto Único Ordenado -TUO- aprobado mediante Decreto Supremo 006-2017-JUS), la mencionada Ley 27444 (LPAG) ha sido posteriormente modificada, siendo su última versión la recogida en el TUO aprobado por el Decreto Supremo 004-2019-JUS.

En ese sentido, salvo mención expresa, al hablar de la LPAG nos referimos al TUO aprobado por el Decreto Supremo 004-2019-JUS. 
al consumidor del Indecopi, hemos identificado dos figuras jurídicas, modificadas e incorporadas a través del referido Decreto Legislativo, que merecen la pena traer a colación y analizar.

Para ello, de forma preliminar desarrollaremos el concepto de carácter común de la LPAG en los procedimientos administrativos, sobre la base de una adecuada interpretación del Decreto Legislativo 1272 y, posteriormente, abordaremos las figuras jurídicas identificadas.

\section{El carácter de norma común de la LPAG}

Si bien los Órganos Resolutivos Administrativos casi no se han pronunciado al respecto $\mathrm{y}$, en general, existe muy poco desarrollo sobre esta modificación sustancial, lo cierto es que el carácter de norma común de la LPAG se desprende de una simple revisión de las modificación que introdujo el Decreto Legislativo 1272 en el Título Preliminar de la misma, tal y como se muestra a continuación:

\begin{tabular}{|c|c|}
\hline $\begin{array}{l}\text { LPAG antes de la modificación del } \\
\text { Decreto Legislativo } 1272\end{array}$ & LPAG actual \\
\hline Artículo II.- Contenido & Artículo II.- Contenido \\
\hline $\begin{array}{l}\text { 1. La presente Ley regula las actuaciones } \\
\text { de la función administrativa del Estado } \\
\text { y el procedimiento administrativo } \\
\text { común desarrollados en las entidades. }\end{array}$ & $\begin{array}{l}\text { 1. La presente Ley contiene normas } \\
\text { comunes para las actuaciones de la } \\
\text { función administrativa del Estado y, } \\
\text { regula todos los procedimientos } \\
\text { administrativos desarrollados en las } \\
\text { entidades, incluyendo los } \\
\text { procedimientos especiales. }\end{array}$ \\
\hline $\begin{array}{l}\text { 2. Los procedimientos especiales } \\
\text { creados y regulados como tales por ley } \\
\text { expresa, atendiendo a la singularidad de } \\
\text { la materia, se rigen supletoriamente por } \\
\text { la presente Ley en aquellos aspectos no } \\
\text { previstos y en los que no son tratados } \\
\text { expresamente de modo distinto. }\end{array}$ & $\begin{array}{l}\text { 2. Las leyes que crean y regulan los } \\
\text { procedimientos especiales no podrán } \\
\text { imponer condiciones menos } \\
\text { favorables a los administrados que } \\
\text { las previstas en la presente Ley. }\end{array}$ \\
\hline $\begin{array}{l}\text { 3. Las autoridades administrativas al } \\
\text { reglamentar los procedimientos }\end{array}$ & $\begin{array}{l}\text { 3. Las autoridades administrativas, al } \\
\text { reglamentar los procedimientos }\end{array}$ \\
\hline
\end{tabular}




\begin{tabular}{|c|c|}
\hline $\begin{array}{l}\text { especiales, cumplirán con seguir los } \\
\text { principios administrativos, así como los } \\
\text { derechos y deberes de los sujetos del } \\
\text { procedimiento, establecidos en la } \\
\text { presente Ley }\end{array}$ & $\begin{array}{l}\text { especiales, cumplirán con seguir los } \\
\text { principios administrativos, así como } \\
\text { los derechos y deberes de los sujetos } \\
\text { del procedimiento, establecidos en la } \\
\text { presente Ley. }\end{array}$ \\
\hline
\end{tabular}

Del texto "original" del Título Preliminar de la LPAG (anterior a la modificación normativa señalada), las autoridades de la Administración Pública podrían entender que, en tanto hayan regulado un procedimiento especial, las normas que le serían aplicables serían las dictadas por la propia entidad, siendo la LPAG de aplicación residual ante los vacíos de la normativa especial. En contraposición a ello, el texto vigente de la mencionada norma es expreso en señalar que la LPAG regula todos los procedimientos administrativos incluyendo los especiales.

Lo expuesto, además, ha sido establecido expresamente en la Exposición de Motivos del Decreto Legislativo 12722:

“Cabe anotar que con las modificaciones efectuadas en lo referido al ámbito de aplicación de la LPAG se busca, tomando en cuenta las experiencias vividas en nuestro país en los últimos años, disponer que esta norma contenga disposiciones comunes para las actuaciones de la función administrativa del Estado $y$ regule todos los procedimientos administrativos desarrollados en las entidades, incluyendo los procedimientos especiales.

Asimismo, se tiene como finalidad que las leyes que crean y regulan los procedimientos especiales no impongan condiciones menos favorables a los administrados que aquellos regulados en la LPAG. No tomar en cuenta lo anterior implicaría ir en contra de la vocación unificadora de la LPAG, aspecto que, es uno de sus objetivos centrales, y todo lo que ello involucra, esto es, asegurar la existencia de un parámetro de unidad como criterio rector de los procedimientos administrativos y la actuación estatal, circunscribir la existencia de procedimientos administrativos especiales a las situaciones que lo justifiquen y establecer un núcleo de aplicación general para todos los procedimientos." (Énfasis agregado)

De acuerdo a ello, es claro que la intención es implantar un conjunto de principios, herramientas y técnicas que establezcan garantías comunes, sobre las cuales se determinarán los procedimientos particulares3. Estas "reglas" son abstractas y universales, sin encontrarse referidas a alguna actividad del Estado en particular,

2 Exposición de Motivos del Decreto Legislativo 1272. 2016. Disponible en: http:/ / www.congreso.gob.pe/Docs/comisiones2016/ConstitucionReglamento/files/exposici $\% \mathrm{C} 3 \% \mathrm{~B} 3 \mathrm{n} \_$de_motivos_dl_1272.pdf

3 GAMERO CASADO, Eduardo. "La estructura de la Legislación sobre Procedimiento Administrativo Común y Régimen Jurídico Básico del Sector público y sus criterios de aplicación". En: GAMERO CASADO, Eduardo (dir.). Tratado de Procedimiento Administrativo Común y Régimen Jurídico Básico del Sector Público. Valencia: Tirant lo blanch, 2017, p. 156-157. 
y se le denomina en doctrina como el "procedimiento administrativo común" 4. A mayor abundamiento, Cosculluela Montaner define lo "común" como la regulación de aplicación general a todas las Administraciones Públicas, que se fundamenta en exigir garantías específicas de un tratamiento común de los administrados ante estas entidades $y$, que sus modos de acción respondan a características comunes que posibiliten una adecuada relación entra ambas5. En esta línea, López Menudo señala que se trata de establecer un común denominador normativo, suficiente para garantizar una básica igualdad de trato6.

En ese sentido, desde la modificación introducida por el Decreto Legislativo 1272, la LPAG se convierte en una norma imperativa que garantiza condiciones mínimas para el desarrollo de todos los procedimientos administrativos, dejando de lado cualquier interpretación referida a que tendría un carácter supletorio.

$\mathrm{Al}$ respecto, es claro que siempre existirán procedimientos con reglas especiales debido a su complejidad. No obstante, como lo hemos señalado, esta especialidad no debe impedir el reconocer que sí existen reglas y principios que, por su particular naturaleza, deben ser considerados comunes a todos los procedimientos y, mucho más aún en la actuación de la Administración Pública en ejercicio de su potestad sancionadora (en donde no existen motivos que puedan justificar apartarse de la norma común).

De acuerdo a ello, conforme indica la Exposición de Motivos del Decreto Legislativo 1272, la decisión de establecer un procedimiento común tiene su principal raíz en la llamada "vocación unificadora" de la norma7, la cual es explicada en términos de Díez Sánchez como aquella por la cual se realiza la triple función de: (i) Asegurar el principio de unidad como criterio rector de los procedimientos, (ii) reconocer la existencia de procedimientos administrativos especiales como adaptaciones del procedimiento común en tanto la peculiaridad

4 Ver CARRILlO DONAIRE, Juan Antonio. “Marco Competencial. Ámbito de aplicación. Capacidad e identificación de los interesados (Título Preliminar, Título I y Disposiciones Finales y Adicionales)". En: GOSÁlbEZ PEQUEÑO, Humberto (dir.). La nueva Ley del Procedimiento Administrativo Común. Madrid: Wolters Kluwer, p.28.

5 COSCULLUELA MONTANER, Luis. “La posición ordinamental de la Ley 30/1992 y los principios y efectos de la misma (Título preliminar y disposiciones adicionales, transitoria, derogatoria y final)". En: SANTA MARÍA PASTOR, Juan Alfonso (director). Comentario sistemático a la Ley de Régimen Jurídico de las Administraciones Públicas y del Procedimiento Administrativo Común (Ley 30/1992, de 26 de noviembre), Madrid: Carperi, págs. 19-51

6 LÓPEZ MENUDO, F. "Los principios generales del procedimiento administrativo. Revista de Administración Pública". En: Revista de Administración Pública. Número 129. SeptiembreDiciembre 1992. Madrid: Centro de Estudios Políticos y Constitucionales, 1992, p. 74. Disponible en: https://dialnet.unirioja.es/descarga/articulo/17143.pdf

7 Exposición de Motivos del Decreto Legislativo 1272. 2016, pp. 3 - 4. Disponible en: http://www.congreso.gob.pe/Docs/comisiones2016/ConstitucionReglamento/files/exposici \%C3\%B3n_de_motivos_dl_1272.pdf 
de cada uno sea justificada; y, (iii) determinar un núcleo de aplicación general e ineludible a todos los procedimientos independientemente de su especialidads.

Sobre la necesidad de establecer una regulación uniforme para los procedimientos administrativos, seguimos a Morón Urbina quien señala que si bien históricamente ha existido una reticencia a establecer una codificación homogénea entre procedimientos especiales (fundamentándose en la mutabilidad de los distintos objetos jurídicos), actualmente, la corriente contemporánea predominante es concebir las regulaciones de Derecho Administrativo como disposiciones esenciales aplicables a las decisiones de la Administración Pública para "hacerlas homogéneas, previsibles y sujetarlas a control de legalidad" 9 . En esa línea, el autor resume acertadamente que "el carácter común de las reglas de la Ley del Procedimiento Administrativo General no excluye la existencia de procedimientos especiales, pero respetando la zona común de los procedimientos"10, pues, afirma que el verdadero propósito de la LPAG ha sido dotar a las autoridades administrativas de pautas comunes.

En suma, previamente a las modificaciones introducidas mediante el Decreto Legislativo 1272, la LPAG se aplicaba de forma obligatoria únicamente cuando la norma especial no establecía regulación sobre el particular, siendo supletoria en los procedimientos especiales. Sin embargo, con las modificaciones introducidas por el mencionado Decreto Legislativo, se estableció -sin lugar a dudas- que las disposiciones de la LPAG prevén condiciones y garantías mínimas que deben ser de aplicación imperativa en cualquier procedimiento especial. De acuerdo a ello, la naturaleza de la LPAG ha cambiado trascendentalmente, siendo actualmente una norma común.

\section{El procedimiento administrativo sancionador}

A priori, debemos mencionar que no es la intención del presente artículo realizar un mayor desarrollo respecto a conceptos propios del procedimiento administrativo, por lo que, en relación a la definición de procedimiento administrativo, nos remitiremos a lo establecido por la LPAG, que lo define como: "el conjunto de actos y diligencias tramitados en las entidades, conducentes a la emisión de un acto administrativo que produzca efectos jurídicos individuales o individualizables sobre intereses, obligaciones o derechos de los administrados" 11.

Por otro lado, el procedimiento administrativo sancionador es concebido como el conjunto de actos destinados a determinar la existencia de responsabilidad administrativa, esto es, la comisión de una infracción y la consecuente aplicación de una sanción. Dicho procedimiento constituye, además, una garantía esencial y

8 DÍEZ SANCHEZ, Juan José. El procedimiento administrativo común y la doctrina constitucional. Madrid: Civitas, 1992, pp. $41-46$.

9 MORÓN URBINA, Juan Carlos. Comentarios a la Ley del Procedimiento Administrativo General. Texto Único Ordenado de la Ley N²7444. Tomo I. Lima: Gaceta Jurídica, pp. 39-41.

10 Ibid. p. 50

11 Artículo 29 de la LPAG 
la vía a través del cual los administrados, a quienes se les imputa la comisión de una infracción, hacen valer sus derechos fundamentales frente a la Administración Pública12.

En pocas palabras, en derecho administrativo sancionador, se entenderá que el procedimiento constituye la vía formal que la Administración deberá seguir para determinar la responsabilidad administrativa ante una infracción e imponer las sanciones correspondientes.

Al respecto, el Tribunal Constitucional 13 ha enfatizado que las entidades de la Administración Pública tienen la obligación de observar los principios del procedimiento sancionador, toda vez que estos garantizan el respeto por los derechos del administrado. En esa misma línea, citando a la Corte Interamericana de Derechos Humanos, el Tribunal Constitucional ha sostenido que la Administración Pública no puede dictar actos administrativos sancionatorios sin otorgar la garantía del debido proceso, por cuanto es un derecho humano el obtener todas las garantías que permitan alcanzar decisiones justas, no estando la administración excluida de cumplir este deber.

Ahora bien, el procedimiento administrativo sancionador se regula, específicamente, en el Capítulo III de la LPAG. Así, el primer artículo del referido capítulo de la LPAG, el artículo 247, establece lo siguiente:

“Artículo 247.- Ámbito de aplicación de este capítulo. -

247.1. Las disposiciones del presente Capítulo disciplinan la facultad que se atribuye a cualquiera de las entidades para establecer infracciones administrativas y las consecuentes sanciones a los administrados.

247.2. Las disposiciones contenidas en el presente Capítulo se aplican con carácter supletorio a todos los procedimientos establecidos en leyes especiales, incluyendo los tributarios, los que deben observar necesariamente los principios de la potestad sancionadora administrativa a que se refiere el artículo 248, así como la estructura y garantías previstas para el procedimiento administrativo sancionador.

Los procedimientos especiales no pueden imponer condiciones menos favorables a los administrados, que las previstas en este Capítulo.

247.3. La potestad sancionadora disciplinaria sobre el personal de las entidades se rige por la normativa sobre la materia". (Énfasis agregado)

12 MINISTERIO DE JUSTICIA Y DERECHOS HUMANOS. Guía práctica sobre el procedimiento administrativo sancionador. Disponible en: https://www.minjus.gob.pe/wpcontent/uploads/2017/07/MINJUS-DGDOJ-GUIA-DE-PROCEDIMIENTOADMINISTRATIVO-SANCIONADOR-2DA-EDICION.pdf

13 Sentencia del 8 de agosto de 2012 recaída en el Expediente $N^{\circ}$ 00156-2012-PHC/TC, segundo párrafo del fundamento jurídico 3. 
Al respecto, traemos a colación el artículo anteriormente citado que introduce el ámbito de aplicación del procedimiento administrativo sancionador, en la medida que conserva una disposición que también debió ser modificada. En efecto, resulta claro que la redacción del artículo mencionado -en particular el numeral 247.2- no es la más acertada, pues, conserva la palabra "supletoria" dentro de su desarrollo. Así, dispone que las disposiciones del capítulo referido al procedimiento sancionador se aplicarán con carácter supletorio a los procedimientos especiales. Debemos mencionar que la redacción de dicho artículo proviene casi en su totalidad de una modificación introducida por el Decreto Legislativo 1029, publicado el 24 de junio de 2008, siendo que el Decreto Legislativo 1272 le añadió la alusión a los procedimientos tributarios.

En relación a ello, en opinión de las autoras, al momento de introducir las modificaciones del Decreto Legislativo 1272, el legislador ha incurrido en un error al mantener la redacción inicial del artículo 247 que señala el carácter supletorio de la LPAG para los procedimientos sancionadores especiales.

Al respecto, debemos referirnos a lo dispuesto en la Exposición de Motivos del Decreto Legislativo 1272 en relación a las modificaciones introducidas al ámbito de aplicación del procedimiento sancionador 14 .

“I.11.3.1 Modificaciones introducidas al ámbito de aplicación del procedimiento sancionador

Ante la comprensión, en rigor equivocada, pero todavía sostenida por algún sector de la doctrina, de querer sostener pautas distintas a las previstas en la LPAG como base para la configuración de todo procedimiento administrativo sancionador, se busca, con la reforma de la LPAG, no quedarse en la sola mención de que los parámetros prescritos en el artículo 229 de la LPAG se aplican a los diferentes procedimientos establecidos en leyes especiales. Ahora, se ve bastante más allá y se hace explícita referencia a la aplicación de estas pautas a todos los procedimientos, incluyendo los de carácter tributario, reforzando la disposición con carácter general ya vigente $(\ldots)^{\prime \prime}$.

Dicho ello, y en virtud de lo expuesto en la sección referida a la naturaleza de norma común de la LPAG, queda claro que la voluntad del legislador es que el carácter común de la LPAG sea así para todos los procedimientos administrativos (incluyendo los sancionadores), desempeñándose como una norma "piso" que deja sentadas las bases comunes que les serán aplicables. Así, considerando la actual redacción del artículo 247. 2, resulta necesario leerlo en su conjunto con el Título Preliminar de la LPAG.

Sin perjuicio a ello, debemos destacar que debido a la especial regulación de los procedimientos sancionadores, el carácter de norma común de la LPAG tiene

14 Ver la exposición de motivos del Decreto Legislativo 1272. Página 48. Disponible en: http:// www.congreso.gob.pe/Docs/comisiones2016/ConstitucionReglamento/files/exposici $\% \mathrm{C} 3 \% \mathrm{~B} 3 \mathrm{n} \_$de_motivos_dl_1272.pdf 
especial relevancia en los mismos. En efecto, dada la propia naturaleza de los procedimientos sancionadores, es necesario aplicar reglas y principios comunes que no podrán ser disminuidos a través de normas especiales, pues constituyen las garantías mínimas que se les otorga a los administrados, por lo que las autoridades administrativas deben necesariamente sujetarse a éstos.

IV. La potestad sancionadora de los Órganos de Protección al Consumidor de Indecopi

Ahora bien, habiendo establecido el carácter común de la LPAG en los procedimientos administrativos sancionadores, corresponde referirnos brevemente a la potestad del Indecopi en relación a los procedimientos de protección al consumidor.

Así, en el artículo 2 del Decreto Legislativo 1033, se señala que el Indecopi tiene la función de proteger los derechos de los consumidores, y, para cumplir sus funciones, se encuentra facultado a supervisar, fiscalizar actividades económicas, imponer sanciones, ordenar medidas preventivas y cautelares, dictar mandatos y medidas correctivas, y resolver controversias.

De acuerdo a lo establecido en la misma norma, será la Comisión de Protección al Consumidor la encargada de velar en primera instancia administrativa por el cumplimiento de las normas que protegen a los consumidores; y, la Sala Especializada en Protección al Consumidor, el órgano encargado de resolver las impugnaciones en segunda instancia administrativa.

En forma complementaria, en el artículo 107 del Código se establece lo siguiente:

“Artículo 107.- Postulación del procedimiento

Los procedimientos administrativos para conocer las presuntas infracciones a las disposiciones contenidas en el presente Código se inician de oficio, bien por propia iniciativa de la autoridad, por denuncia del consumidor afectado o del que potencialmente pudiera verse afectado, o por una asociación de consumidores en representación de sus asociados o poderdantes o en defensa de intereses colectivos o difusos de los consumidores. En este último caso, la asociación de consumidores actúa como tercero legitimado sin gozar de las facultades para disponer derechos de los consumidores afectados, salvo de sus asociados o de las personas que le hayan otorgado poder para tal efecto. Tanto el consumidor constituido como parte como el tercero legitimado pueden participar en el procedimiento e interponer los recursos contra la resolución que deniegue el inicio del procedimiento y contra cualquier otra resolución impugnable que les produzca agravio. El procedimiento administrativo en materia de protección al consumidor se inicia con la notificación de la imputación de cargos al posible infractor". (Énfasis agregado) 
Así, se resalta que los procedimientos en materia de protección al consumidor, por su propia naturaleza, en tanto son pasibles de concluir con la imposición de una sanción (multa) ante la vulneración de un bien constitucionalmente protegido15, son procedimientos administrativos sancionadores $\mathrm{y}$, como tales, deben ceñirse a las normas "piso" que se establecen en la LPAG, particularmente en el Capítulo III.

Lo anterior no es un tema que resulte desconocido para el legislador del Código, pues, esto se refleja en las modificaciones que fueron introducidas en el Código desde la promulgación del Decreto Legislativo 1272 (mediante Decreto Legislativo 1308 y, posteriormente, mediante Decreto Legislativo 1390). Tales modificaciones, reflejan que el Código ha intentado incorporar la voluntad del legislador establecida en el Decreto Legislativo 1272, buscando homologar las condiciones que se encuentran en la LPAG.

A lo largo de las siguientes secciones, estudiaremos dos instituciones jurídicas propias del procedimiento administrativo sancionador que fueron incorporadas/modificadas mediante el Decreto Legislativo 1272 y daremos algunos alcances de cómo han venido siendo tratadas por los Órganos Resolutivos del Indecopi. La primera, la caducidad, recién fue incorporada a nuestro ordenamiento jurídico mediante el Decreto Legislativo 1272, mientras que la segunda figura elegida, la subsanación, pasó de ser un atenuante a ser eximente de responsabilidad con las modificaciones introducidas por el Decreto Legislativo 1272 (y la posterior modificación del Código).

\section{La caducidad en los procedimientos administrativos sancionadores}

El transcurso del tiempo es un hecho trascendental que afecta cualquier relación contractual. En efecto, el transcurso del tiempo es un hecho jurídico natural que en sí mismo o en concurrencia con otros hechos genera efectos jurídicos de trascendental importancia16. Estos son, entre otros, la posibilidad de crear, modificar o extinguir derechos u obligaciones. Además, estos efectos pueden incidir tanto en las relaciones privadas como en las relaciones de derecho público que surgen con motivo del inicio de un procedimiento administrativo.

Ahora bien, para fines del presente artículo, nos referiremos a las implicancias del transcurso del tiempo en los procedimientos administrativos. Así, el transcurso del tiempo asociado a "la inactividad de la administración produce dos efectos favorables al particular: por un lado (...) la prescripción de las infracciones; y, por

15 Conforme se indica en el artículo 65 de la Constitución Política del Perú: El Estado defiende el interés de los consumidores y usuarios. Para tal efecto garantiza el derecho a la información sobre los bienes y servicios que se encuentran a su disposición en el mercado. Asimismo vela, en particular, por la salud y la seguridad de la población.

16 VIDAL RAMÍREZ, Fernando. Prescripción extintiva y caducidad. Cuarta edición. Lima: Gaceta Jurídica, 2002, p. 17. 
otro, la caducidad del procedimiento ya iniciado (o perención)"17. La prescripción siempre tuvo reconocimiento en el ordenamiento administrativo general, sin embargo, la caducidad - a pesar de su utilidad práctica - no había sido objeto de atención por parte del legislador.

Si bien ambas figuras son consecuencia directa del transcurso del tiempo y forman parte del derecho administrativo sancionador, se debe tener especial cuidado en no confundirlas, pues, las mismas operan en ámbitos distintos:

- La caducidad incide sobre el procedimiento administrativo sancionador en sí mismo, en el tiempo de duración del mismo.

- La prescripción afecta a la misma potestad (facultad) sancionadora con que cuenta la Autoridad Administrativa para determinar la existencia de una infracción administrativa e imponer la sanción respectiva.

Ahora bien, para los fines del presente artículo, nos referiremos únicamente a la figura de la caducidad.

Así, la figura de la caducidad se encuentra regulada en el artículo 259 de la LPAG, pudiendo ser definida como aquella que “origina la terminación anormal y anticipada de un procedimiento, debido a la inactividad de la autoridad competente prolongada en su trámite que ocasiona que el plazo establecido para su culminación se venza, adelantando el término del procedimiento por mandato de la ley" 18.

Puntualmente, el artículo 259 de la LPAG establece lo siguiente:

“Artículo 259.- Caducidad administrativa del procedimiento sancionador

1. El plazo para resolver los procedimientos sancionadores iniciados de oficio es de nueve (9) meses contado desde la fecha de notificación de la imputación de cargos. Este plazo puede ser ampliado de manera excepcional, como máximo por tres (3) meses, debiendo el órgano competente emitir una resolución debidamente sustentada, justificando la ampliación del plazo, previo a su vencimiento. La caducidad administrativa no aplica al procedimiento recursivo.

Cuando conforme a ley las entidades cuenten con un plazo mayor para resolver la caducidad operará al vencimiento de este.

2. Transcurrido el plazo máximo para resolver, sin que se notifique la resolución respectiva, se entiende automáticamente caducado el procedimiento y se procederá a su archivo.

3. La caducidad administrativa es declarada de oficio por el órgano competente. El administrado se encuentra facultado para solicitar la

17 NIETO GARCÍA, Alejandro. Derecho administrativo sancionador. Quinta edición. Madrid: Tecnos, 2012, p. 550.

18 MORÓN URBINA, Juan Carlos. Comentarios a la Ley del Procedimiento Administrativo General. Texto Único Ordenado de la Ley N²7444. Tomo II. Lima: Gaceta Jurídica, 2018, p. 527 y 530. 
caducidad administrativa del procedimiento en caso el órgano competente no la haya declarado de oficio.

4. En el supuesto que la infracción no hubiera prescrito, el órgano competente evaluará el inicio de un nuevo procedimiento sancionador. El procedimiento caducado administrativamente no interrumpe la prescripción.

5. La declaración de la caducidad administrativa no deja sin efecto las actuaciones de fiscalización, así como los medios probatorios que no puedan o no resulte necesario ser actuados nuevamente. Asimismo, las medidas preventivas, correctivas y cautelares dictadas se mantienen vigentes durante el plazo de tres (3) meses adicionales en tanto se disponga el inicio del nuevo procedimiento sancionador, luego de lo cual caducan, pudiéndose disponer nuevas medidas de la misma naturaleza en caso se inicie el procedimiento sancionador".

De acuerdo a la citada disposición, debemos partir de la premisa que la caducidad opera de manera automática. Así, únicamente se deberían cumplir las siguientes condiciones: (i) la falta de resolución del procedimiento por parte de la autoridad de primera instancia competente; $y$, (ii) el transcurso del tiempo establecido por la norma. Consideramos que la norma es bastante clara al respecto.

En síntesis, la caducidad es aquella institución jurídica que de producirse inhabilita a la autoridad para continuar con el procedimiento administrativo. En ese sentido, la caducidad es la figura jurídica que establece el tiempo máximo dentro del cual se debe instruir y resolver un procedimiento sancionador $\mathrm{y}$, habiendo transcurrido este tiempo, la Autoridad Administrativa ya no cuenta con la facultad para continuar con ese procedimiento.

Al respecto, debemos señalar la forma en la cual se ha pronunciado la Sala Especializada en Protección al Consumidor del Tribunal del Indecopi (en adelante, la Sala) sobre la aplicación de esta figura. Así, en el caso tramitado bajo Expediente No. 0345-2017/CC2, el imputado alegó en el trámite del procedimiento recursivo que en la primera instancia había transcurrido el plazo de caducidad, por lo que correspondía concluir el procedimiento.

En el referido caso, mediante Resolución No. 0099-2019/SPC-INDECOPI de fecha 14 de enero de 201919, la Sala se pronunció de la siguiente manera sobre la figura de la caducidad:

“De esta forma, la caducidad en los procedimientos de oficio (por iniciativa de la autoridad) garantiza al proveedor denunciado contar con una decisión sobre su responsabilidad dentro de un plazo específico y a la vez promueve la proactividad y eficiencia de la Administración Pública en la persecución de una infracción, siendo distinto el caso de los procedimientos iniciados a solicitud de parte, pues es un procedimiento que tiene una naturaleza

19 Cabe indicar que dicho pronunciamiento sigue un criterio similar desarrollado en la Resolución No. 3401-2018/SPC de fecha 5 de diciembre de 2018. 
especial, ya que el consumidor tiene la expectativa de la tutela por parte de la administración.

En efecto, cuando se trata de un procedimiento por iniciativa de parte, en este caso un consumidor, esta Sala considera que no se podría aplicar la caducidad del procedimiento, pues se estaría castigando a un consumidor interesado -que ha acudido a la autoridad administrativa para la tutela de un derecho- por una circunstancia que no le es atribuible (la falta de actuación oportuna de la autoridad).

En este punto conviene tener en cuenta el Principio Pro Consumidor, el cual establece lo siguiente: 'Principio Pro Consumidor. En cualquier campo de su actuación, el Estado ejerce una acción tuitiva a favor de los consumidores. En proyección de este principio en caso de duda insalvable en el sentido de las normas o cuando exista duda en los alcances de los contratos por adhesión y los celebrados en base a cláusulas generales de contratación, debe interpretarse en sentido más favorable al consumidor.

Por ende, a criterio de este Colegiado, las disposiciones sobre caducidad, contenidas en el artículo $257^{\circ}$ del TUO de la LPAG, deben ser entendidas, como aplicables únicamente a aquellos procedimientos de oficio por iniciativa de la autoridad, pues en estos procedimientos: (i) no existe una pretensión particular de un consumidor que se vea perjudicado por la falta de diligencia de la autoridad; $y$, (ii) constituye un mecanismo que opera en garantía del administrado (proveedor) quien tiene la expectativa de que exista un límite temporal para que su situación jurídica se vea resuelta“. (Énfasis agregado)

Tal como se puede apreciar, el pronunciamiento anteriormente referido se sustentaría, para la Sala, en la especial naturaleza de los procedimientos en materia de protección al consumidor y el derecho constitucional de los consumidores de ver tutelados sus derechos en el marco de las relaciones de consumo.

Sobre el particular, en primer lugar, debemos resaltar que todos los procedimientos de protección al consumidor que se tramitan ante el Indecopi son siempre procedimientos sancionadores de oficio, sean iniciados por propia iniciativa de la autoridad como promovidos por alguna denuncia20. De acuerdo a ello, no es correcto hacer un "diferencia" donde la ley no lo establece. En efecto, la norma en mención no establece la distinción plasmada por la Sala, sino únicamente se incluye que esta figura opera en los procedimientos sancionadores de oficio. Un procedimiento de protección al consumidor iniciado por iniciativa de parte continua siendo un procedimiento sancionador de oficio.

Así, la interpretación de la Sala relacionada a que la caducidad únicamente opera en casos iniciados por iniciativa de la autoridad, se fundamenta en el principio pro-consumidor y pondera un derecho constitucionalmente reconocido. En efecto, el Estado tiene la obligación ejercer una acción tuitiva a favor de los consumidores

20 Artículo 107 del Código. 
y la inacción de la administración no puede afectar la tutela efectiva de este derecho. Al respecto, el Tribunal Constitucional ha establecido:

"La Constitución reconoce el derecho de defenderse de los consumidores y usuarios en los casos de transgresión o desconocimiento de sus legítimos intereses; es decir, reconoce el derecho de exigir al Estado una actuación determinada cuando se produzca alguna forma de amenaza o afectación efectiva de los derechos de consumidor o usuario, incluyendo la capacidad de acción contra el propio proveedor" 21.

De acuerdo a ello, si nuestro análisis se circunscribe únicamente a la valoración y la importancia de este derecho es claro que el criterio de la Sala no resulta cuestionable. No obstante, debemos preguntarnos: ¿El reconocimiento de derechos a favor del denunciante (consumidor) legitima a la Autoridad Administrativa a interpretar la norma en perjuicio de los derechos del imputado?

Adicionalmente a ello, se debe tener en cuenta que el principal objetivo de la figura de la caducidad es de dotar de eficacia las actuaciones de la Administración. Es decir, no debemos de olvidar que la aplicación de la caducidad representa un mecanismo donde son los propios administrados (tanto proveedores como consumidores) los beneficiados, pues, limita y controla la debida actuación de la Administración Pública. Además, el propio Tribunal Constitucional reconoce que el Estado está obligado a "establecer procedimientos apropiados para que, en su seno, los consumidores y usuarios puedan, mediante recursos sencillos, rápidos y efectivos, solicitar la protección de aquellos derechos e intereses" 22, es decir, se encuentra expresamente reconocido que es necesario contar con mecanismos rápidos y efectivos, siendo precisamente la caducidad la figura mediante la cual el ordenamiento jurídico le impone a la Administración Pública la labor de dirigir sus actuaciones de forma eficaz. Sin embargo, con pronunciamientos como el anteriormente citado, se termina por afectar tanto la seguridad jurídica del denunciado, como la eficacia en la actuación de la Administración.

En esa línea, somos de la opinión que la interpretación dada por la Sala, si bien tiene una esencia totalmente justificable, no ha sido plasmada de una forma totalmente correcta. Es decir, no somos enfáticas en señalar que el pronunciamiento es totalmente errado, pues, se fundamenta en un pilar importante. No obstante a ello, consideramos que hace falta una mayor profundidad en su desarrollo, pues, se está ignorando una regla "piso" - la caducidad- establecida por la LPAG, dejándose de lado así una garantía mínima común que debe regir en todos los procedimientos administrativos sancionadores.

\section{La subsanación voluntaria como eximente de responsabilidad}

21 Sentencia de amparo expedida por el Tribunal Constitucional en el Expediente $\mathrm{N}^{\circ} 0858-2003$ AA/TC del 24 de marzo de 2004.

22 Ídem. 
La segunda institución a estudiar en el presente artículo es la subsanación de las infracciones. Hemos considerado referirnos a esta figura en tanto refleja un cambio en la voluntad legislativa marcado por el Decreto Legislativo 1272.

De manera previa a la promulgación de dicha norma, en el Código se regulaba la subsanación voluntaria previa a la notificación de imputación de cargos como una atenuante especial, establecida en el artículo 112 del mismo. Así, anteriormente era aplicada como atenuante por los Órganos Resolutivos del Indecopi23. Sin embargo, el Decreto Legislativo 1272 incorporó dicha circunstancia como un eximente de responsabilidad, lo cual resulta una condición más beneficiosa para los administrados, por lo que dicha condición fue considerada en la modificación del Código (Decreto Legislativo 1308 y, posteriormente, precisada por el Decreto Legislativo 1390).

$\mathrm{Al}$ respecto, consideramos que el referido cambio legislativo, refleja un cambio en cómo se entiende la potestad sancionadora y la finalidad de los procedimientos sancionadores, como se verá líneas más adelante.

Actualmente en el numeral 1 del artículo 257 de la LPAG se estipula lo siguiente:

“Artículo 257.- Eximentes y atenuantes de responsabilidad por infracciones

1. Constituyen condiciones eximentes de la responsabilidad por infracciones las siguientes:

$(\ldots)$

f) La subsanación voluntaria por parte del posible sancionado del acto u omisión imputado como constitutivo de infracción administrativa, con anterioridad a la notificación de la imputación de cargos a que se refiere el inciso 3) del artículo 255".

Asimismo, la modificación del Código24 incorpora la figura de la subsanación en el literal f) del artículo 108 (texto vigente):

“Artículo 108.- Infracciones administrativas.

Constituye infracción administrativa la conducta del proveedor que transgrede las disposiciones del presente Código, tanto si ello implica violar los derechos reconocidos a los consumidores como incumplir las obligaciones que estas normas imponen a los proveedores. También son supuestos de infracción administrativa el incumplimiento de acuerdos

23 Se listan a continuación Resoluciones en las cuales se discutió la aplicación de un atenuante por subsanación voluntaria: 42-2016/SPC-INDECOPI, 25-2016/SPC-INDECOPI y 3323-2016/SPCINDECOPI.

24 Cabe señalar que mediante Decreto Legislativo 1308 se incorporó la subsanación voluntaria como eximente de responsabilidad y, posteriormente, mediante Decreto Legislativo 1390 se precisó que lo señalado no aplicaría para casos en los que se ponga en riesgo la vida, salud o seguridad de las personas, así como en casos de discriminación. Para efectos del presente artículo, se está considerando el texto vigente de la norma, es decir, posterior a la promulgación del Decreto Legislativo 1390. 
conciliatorios o cualquier otro acuerdo que de forma indubitable deje constancia de la manifestación de voluntad expresa de las partes de dar por culminada la controversia, de laudos arbitrales, y aquellos previstos en el Decreto Legislativo $N^{\circ}$ 807, Ley sobre Facultades, Normas y Organización del Indecopi, y en las normas que lo complementen o sustituyan.

Sin que la presente enumeración sea taxativa, pondrán fin al procedimiento administrativo la resolución de la autoridad administrativa que declara la improcedencia de la denuncia de parte en los siguientes supuestos:

\section{$(\ldots)$}

f) Si el proveedor subsana o corrige la conducta constitutiva de infracción administrativa denunciada con anterioridad a la notificación de la imputación de cargos. Lo señalado no aplica en los casos que se haya puesto en riesgo la vida, salud o seguridad de las personas o se trate de supuestos de discriminación".

De lo anterior, se advierte que, para aplicar el mencionado eximente, será necesario que confluyan tres elementos: i. El elemento objetivo: Que se dé la subsanación de un hecho infractor, ii. el elemento subjetivo: Que sea voluntaria; y, iii. el elemento circunstancial o temporal: Que sea previa a la notificación de la imputación de cargos del procedimiento administrativo sancionador.

A continuación nos referiremos, a mayor detalle, a cada uno de ellos.

\section{i. Elemento objetivo}

De los elementos citados, resulta de mayor complejidad analizar el primero de ellos, toda vez que la norma no ha sido explícita en indicar en qué consiste la subsanación de la conducta infractora. Lo único que se tiene claro es que para que se configure una subsanación, deberá existir una conducta infractora pasible de ser sancionada, entendiéndose la infracción administrativa como aquella conducta (de acción u omisión) que contraviene lo dispuesto por la norma previamente tipificada.

De acuerdo con la definición del Diccionario de la Lengua Española, "subsanar" significa "reparar o remediar un defecto" o "resarcir un daño", pero dicha definición no alcanza para entender a plenitud qué debe verificarse en un caso de subsanación. Entonces, corresponde preguntarnos: ¿Cuáles son los alcances de la subsanación? ¿El cese de la conducta infractora? ¿El arrepentimiento? ¿La reversión de los efectos causados?

Sobre este punto, el Ministerio de Justicia y Derechos Humanos (en adelante, Minjus) ha señalado lo siguiente:

"Cabe indicar que este supuesto no solo consiste en el cese de la conducta infractora, sino que, cuando corresponda, la subsanación implica la reparación de las consecuencias o efectos dañinos al bien jurídico protegido derivados de la conducta infractora. Ello con la finalidad de no 
generar impunidad y evitar que el imputado se apropie del beneficio ilícitamente obtenido por la infracción"25. (Énfasis agregado)

De ello, se advierte que la postura defendida por el Minjus implica interpretar la norma de manera que no solo deba repararse la conducta en sí misma, sino también los efectos ocasionados por ésta.

Por otro lado, Morón Urbina26 señala lo siguiente:

“(...), este eximente puede ser aplicado a ilícitos que son acciones positivas y no solo omisiones (...), a infracciones menores o graves, pues la distinción de magnitud no hace a la subsanación de la infracción, a las infracciones de mera conducta o de perjuicio efectivo. Toda infracción es jurídicamente subsanable, lo que impide o dificulta la subsanibilidad es la posibilidad do no de revertir los efectos dañosos producidos. (...) no se subsana con solo dejar de incurrir en la práctica incorrecta, en arrepentirse de ello, sino en verdaderamente identificar el daño realmente producido al bien público protegido y revertirlo. Por otro lado, aquí no puede exigirse resarcir supuestos daños potenciales, subjetivos o abstractos, como haber puesto en riesgo al bien, la confiabilidad de la información, etc."

Por ello, para el citado autor, en tanto a nivel abstracto siempre sería posible subsanar las conductas, el sentido actual de la norma no es desincentivar la comisión de ilícitos, sino buscar que el administrado adecúe su comportamiento al ordenamiento jurídico de manera absolutamente voluntaria y sin que medie un requerimiento por parte de la Autoridad Administrativa27.

Nuestra opinión sobre el particular es que no debe diferenciarse las conductas por la cantidad de afectados o el impacto del daño causado, como se realiza en algunas entidades de la Administración Pública28. Por el contrario, para evaluar si una infracción puede ser subsanada, consideramos necesario analizar la naturaleza de las conductas imputadas, en cada caso concreto, a fin de verificar si el hecho infractor se habría agotado.

Así, sobre la aplicación de la subsanación voluntaria en los procedimientos en materia de consumidor, hemos considerado pertinente desarrollar algunos ejemplos que reflejan los criterios seguidos por los Órganos Resolutivos del Indecopi:

25 MINISTERIO DE JUSTICIA Y DERECHOS HUMANOS. Guía práctica sobre el procedimiento administrativo sancionador. Disponible en: https://www.minjus.gob.pe/wpcontent/uploads/2017/07/MINJUS-DGDOJ-GUIA-DE-PROCEDIMIENTO-

ADMINISTRATIVO-SANCIONADOR-2DA-EDICION.pdf

26 MORÓN URBINA, Juan Carlos. Comentarios a Ley del Procedimiento Administrativo General. Texto Único Ordenado de la Ley N² 27444. Tomo II. Lima: Gaceta Jurídica MORÓN URBINA, Juan Carlos. Comentarios a Ley del Procedimiento Administrativo General. Texto Único Ordenado de la Ley N²27444. Tomo II. Lima: Gaceta Jurídica, 2017, p. 513.

27 Ídem. p. 523.

28 A modo de ejemplo en el artículo 20 del Reglamento de Supervisión del OEFA, se menciona que, para archivar, la subsanación voluntaria deberá acreditarse en una infracción de impacto leve. 


\begin{tabular}{|c|c|c|c|c|}
\hline $\mathbf{N}^{\circ}$ & Resolución & $\begin{array}{l}\text { Infracción } \\
\text { imputada }\end{array}$ & $\begin{array}{c}\text { Criterio del } \\
\text { órgano resolutivo }\end{array}$ & ¿Subsanable? \\
\hline 1 & $\begin{array}{l}\text { 0532- } \\
\text { 2019/SPC- } \\
\text { INDECOPI }\end{array}$ & $\begin{array}{l}\text { Realizar cobros } \\
\text { por concepto de } \\
\text { cuotas cobradas } \\
\text { por adelantado } \\
\text { por concepto de } \\
\text { desgravamen, } \\
\text { pese a que no } \\
\text { correspondía. }\end{array}$ & $\begin{array}{l}\text { Se archiva la } \\
\text { imputación } \\
\text { porque devolvió } \\
\text { los pagos por } \\
\text { desgravamen de } \\
\text { manera previa al } \\
\text { inicio del } \\
\text { procedimiento. }\end{array}$ & $\begin{array}{lr}\text { Sí, en tanto se } \\
\text { devuelva a los } \\
\text { consumidores } \\
\text { monto pagado. }\end{array}$ \\
\hline 2 & $\begin{array}{l}484- \\
\text { 2019/SPC- } \\
\text { INDECOPI }\end{array}$ & $\begin{array}{l}\text { No contar con el } \\
\text { Libro de } \\
\text { Reclamaciones } \\
\text { y su respectivo } \\
\text { Aviso }\end{array}$ & $\begin{array}{l}\text { Sí podía ser } \\
\text { subsanable la } \\
\text { infracción, pero no } \\
\text { se aplicó el } \\
\text { eximente por un } \\
\text { tema probatorio. }\end{array}$ & $\begin{array}{l}\text { Sí, bastaría colocar el } \\
\text { aviso del Libro de } \\
\text { Reclamaciones. }\end{array}$ \\
\hline 3 & $\begin{array}{l}\text { 153- } \\
2019 / C C 3\end{array}$ & $\begin{array}{l}\text { No consignar } \\
\text { en los boletos } \\
\text { de viaje } \\
\text { determinada } \\
\text { información de } \\
\text { índole legal } \\
\text { relevante. }\end{array}$ & $\begin{array}{l}\text { Se archivó la } \\
\text { imputación } \\
\text { porque se subsanó } \\
\text { de manera previa } \\
\text { al inicio, } \\
\text { incluyendo la } \\
\text { información } \\
\text { faltante en los } \\
\text { boletos de viaje. }\end{array}$ & $\begin{array}{l}\text { Sí, en tanto bastaría } \\
\text { colocar la } \\
\text { información en los } \\
\text { boletos. }\end{array}$ \\
\hline 4 & $\begin{array}{l}\text { 2025- } \\
\text { 2019/SPC- } \\
\text { Indecopi }\end{array}$ & $\begin{array}{l}\text { Establecer un } \\
\text { trato desigual } \\
\text { injustificado y } \\
\text { basado en la } \\
\text { edad de los } \\
\text { consumidores, } \\
\text { impidiendo el } \\
\text { acceso de éstos } \\
\text { a determinados } \\
\text { servicios. }\end{array}$ & $\begin{array}{l}\text { La eliminación del } \\
\text { requisito la página } \\
\text { web del proveedor } \\
\text { no es una } \\
\text { subsanación, en } \\
\text { tanto se verifica } \\
\text { que en la práctica } \\
\text { seguían aplicando } \\
\text { el requisito } \\
\text { supuestamente } \\
\text { eliminado. }\end{array}$ & $\begin{array}{l}\text { No, porque si bien } \\
\text { puede retirarse el } \\
\text { requisito, } \\
\text { importante es que en } \\
\text { la práctica no siga } \\
\text { aplicándose, siendo } \\
\text { que solamente } \\
\text { procedería } \\
\text { eximente si se } \\
\text { hubiera cesado la } \\
\text { conducta. }\end{array}$ \\
\hline
\end{tabular}

Adicionalmente a los casos citados, traemos a colación un reciente pronunciamiento expedido por la Sala sobre la aplicación de la subsanación 
voluntaria en los procedimientos en materia de consumidor. El caso corresponde a una infracción por establecer medidas ilegales para el cobro de las pensiones por la campaña escolar del año 2017. Al respecto, la Sala estableció que aun si el administrado (proveedor del servicio) acreditase haber corregido su conducta para el año siguiente (antes de la notificación de la imputación de cargos, claro está), los efectos de la conducta imputada (el hecho de que los consumidores conocían sobre dichas medidas durante todo el año 2017) no se verían reparados, por lo que no correspondería aplicar el eximente de responsabilidad.

Así, través de la Resolución No. 2320-2019/SPC de fecha 26 de agosto de 201929, la Sala señaló lo siguiente:

“35. Asimismo, corresponde señalar que, la infracción referida al condicionamiento de no incluir en los documentos evaluatorios las calificaciones por periodos no pagados, es una infracción que se configuró desde el momento en que se puso en conocimiento de los padres de familia tal disposición, debido a que la conducta objeto de análisis constituye una infracción de mera actividad (...).

41. Por otro lado, en lo que respecta al alegato del Colegio consistente en que todas las infracciones eran jurídicamente subsanables, esta Sala considera pertinente señalar que tal afirmación no resulta cierta. Ello, en tanto el carácter subsanable o no de una conducta dependerá de la oportunidad en la que esta consumó sus efectos, siendo que en el presente caso, este se materializó durante el año escolar 2017.

42. De lo expuesto, se desprende que la subsanación solo podrá realizarse cuando los efectos de la conducta infractora todavía puedan ser reparados, lo que implica que, una vez que los efectos se hayan agotado como en el presente caso, no existirá la posibilidad de subsanar la conducta infractora.

43. Asimismo, es pertinente indicar que si bien en el literal f) del artículo 255 del TUO de la LPAG, no hace alguna precisión respecto del tipo de infracción sobre el cual procede o no la subsanación, en tanto dicha norma únicamente tiene como finalidad indicar un supuesto de exención de responsabilidad; lo cierto es que tanto en la doctrina como en reiterada jurisprudencia se ha desarrollado que existen conductas que por su propia naturaleza no resultan subsanables.

$(\ldots)^{\prime \prime}$. (Énfasis agregado) 
A modo de ejemplo, si seguimos el criterio plasmado por la Sala, podemos considerar que la aplicación del eximente de responsabilidad en las siguientes infracciones tendría el siguiente resultado:

\begin{tabular}{|l|l|l|}
\hline $\mathbf{N}^{\circ}$ & \multicolumn{1}{|c|}{ Infracción imputada } & \multicolumn{1}{c|}{ ¿Subsanable? } \\
\hline 1 & $\begin{array}{l}\text { Negativa de entrega del Libro } \\
\text { de Reclamaciones a algún } \\
\text { consumidor en particular }\end{array}$ & $\begin{array}{l}\text { No, la negativa a entregar se dio en un } \\
\text { momento en particular, impidiendo al } \\
\text { consumidor acceder al Libro en el } \\
\text { momento adecuado. }\end{array}$ \\
\hline 3 & $\begin{array}{l}\text { Cobrar en exceso algún monto } \\
\text { a los consumidores }\end{array}$ & $\begin{array}{l}\text { Sí, en tanto se devuelva a todos el monto } \\
\text { pagado en exceso. }\end{array}$ \\
\hline 4 & $\begin{array}{l}\text { Hibro de Reclamaciones } \\
\text { pasajeros de un bus al no haber } \\
\text { seguido los protocolos de } \\
\text { seguridad necesarios }\end{array}$ & $\begin{array}{l}\text { Sí, bastaría colocar el aviso del Libro de } \\
\text { Reclamaciones. } \\
\text { al un aviso destarse de infracciones de peligro, } \\
\text { estas quedan consumadas al crear dicho } \\
\text { peligro, sin haber posibilidad de } \\
\text { subsanación de la conducta. }\end{array}$ \\
\hline $\begin{array}{l}\text { Discriminar a una persona } \\
\text { local por una condición física }\end{array}$ & $\begin{array}{l}\text { No, porque aún si le dieran ingreso al } \\
\text { local, el daño causado a la dignidad de la } \\
\text { persona no es reparable. }\end{array}$ \\
\hline
\end{tabular}

Al respecto, consideramos que es clara la aplicación del eximente de responsabilidad cuando el hecho infractor se encontraba agotado. No obstante, consideramos que en caso que el hecho infractor cuente con efectos en el tiempo que ya fueron agotados, no se deberá determinar per se que éstos no son subsanables, sino que es preciso evaluar caso por caso basándose en la naturaleza de la infracción, a fin de verificar si se cumple el elemento objetivo del eximente de responsabilidad. Así, consideramos que es trascendental analizar la naturaleza de las conductas imputadas, en cada caso concreto, a fin de verificar si el hecho infractor en sí mismo se habría agotado.

De otra parte, cabe acotar que, si bien las modificaciones han buscado incorporar lo establecido en la LPAG respecto al eximente de responsabilidad por subsanación voluntaria, mediante el Decreto Legislativo 1390 se añadió que este 
eximente no será aplicable cuando los bienes jurídicos afectados sean la vida, salud o seguridad de las personas, o se trate de un acto de discriminación.

En ese sentido advertimos que el Código ha puesto límites a la aplicación del supuesto de eximente de responsabilidad analizado, imponiendo una condición que resulta menos favorable a los administrados que la prevista en la LPAG. Es claro que la intención del legislador al incorporar dichas limitaciones ha sido cuidar determinados bienes jurídicos más sensibles como puede ser la vida, integridad, o igualdad. Sin embargo, conforme a lo desarrollado en la sección referida al carácter común de la LPAG, consideramos que no estamos frente a una aplicación del todo correcta. Lo cierto es que si los Órganos de Protección al Consumidor efectuaran un análisis caso por caso, en vez de -a priori- dejarse llevar por el bien jurídico identificado, tendríamos resultados más próximos al sentido de la norma común (que no restringe bienes jurídicos), sin descuidar la importancia de la vida o la integridad de los consumidores.

\section{ii. Elemento subjetivo}

En segundo lugar, respecto al elemento subjetivo, se requiere que la subsanación sea voluntaria, sin embargo, la norma tampoco nos da una aproximación clara respecto a cómo entender la voluntariedad del administrado. Ante ello, algunas entidades de la Administración Pública han estipulado disposiciones referidas al tema. Por ejemplo, en el Reglamento de Fiscalización, Infracciones y Sanciones del Organismo Supervisor de la Inversión Privada en Telecomunicaciones - Osiptel, y en el Reglamento de Supervisión del - OEFA, se establece que se pierde el carácter voluntario de la subsanación si esta se produce cuando ha mediado algún requerimiento de subsanación o de cumplimiento de la obligación por parte de la Autoridad, sea establecido en carta, resolución o en la etapa de supervisión.

Al respecto, sostenemos que la voluntariedad en el eximente de responsabilidad analizado deberá referirse a la subsanación voluntaria por parte del administrado, sin que sea producto de una orden de la Autoridad Administrativa dentro de la tramitación de un procedimiento administrativo sancionador, plasmada a través de una medida correctiva.

Sobre este punto, consideramos pertinente distinguir algunas aristas de la voluntariedad en contraposición con la actividad de fiscalización. Esta última se encuentra definida en la LPAG como el conjunto de actos y diligencias de investigación, supervisión, control o inspección sobre el cumplimiento de las obligaciones exigibles a los administrados, encontrándose su regulación común entre los artículos 239 y 246 de la LPAG.

Ahora bien, consideramos que la actividad de la fiscalización podría promover en los administrados la toma de decisiones orientadas a la subsanación de los incumplimientos que se evidencien. A modo de ejemplo, a través de la Resolución 
No. 153-2019/CC3 de fecha 12 de julio de 2019, la Comisión de Protección al Consumidor No. 3 eximió de responsabilidad al imputado, en tanto éste incluyó la información relevante faltante en un boleto de transporte terrestre, de forma posterior a las inspecciones realizadas por los fiscalizadores pero antes de la notificación de la imputación de cargos. Es claro que el administrado tomó conocimiento de la infracción durante la supervisión, sin embargo, la decisión de corregir su conducta surgió de él mismo, no pudiendo desacreditarse su voluntariedad por haberse realizado dentro de la etapa de supervisión.

De la misma manera, al pronunciarnos sobre el término "voluntario", consideramos también hacer algunas precisiones frente a los llamados "recalls". De manera general, un recall es cuando, ante un riesgo no previsto o imprevisible, el proveedor advierte a los consumidores sobre el mismo y dispone una lista de medidas para eliminar o reducir el riesgo, las cuales abarcan un llamado a reparación o sustitución, o incluso un retiro del mercado del producto en cuestión $^{30}$. El procedimiento a seguir se encuentra regulado en el Decreto Supremo 050-2016-PCM.

Se debe tener en cuenta que en un recall no se ha materializado una infracción al deber de seguridad establecido en el Código, sino que solamente se ha detectado el riesgo que se pueda presentar alguna situación en la que se ponga en peligro al consumidor. Por ejemplo, si en la producción masiva de un determinado lote de vehículos se hubiera detectado que existe un riesgo consistente en que las bolsas de aire (airbags) no se activen adecuadamente ante un impacto, correspondería que se aplique un procedimiento de recall. Así, en ese caso, el proveedor deberá actuar conforme indica la normativa correspondiente $y$, de incumplirla, podría ser sancionado, únicamente, respecto al incumplimiento del procedimiento de recalls, mas no por la presencia de algún defecto.

En esa lógica, consideramos que cumplir con un procedimiento de recall no eximiría al proveedor de responsabilidad si en efecto se presentase el defecto que atenta contra la seguridad de los consumidores. De acuerdo a ello, no podría alegar un eximente de responsabilidad por subsanación previa, en tanto al momento de realizar el procedimiento de recall no había una infracción a subsanar.

No obstante a ello, en nuestra opinión, aplicar un correcto procedimiento de recall debería ser considerado por el Órgano Resolutivo como un atenuante de la multa, en caso se materialice la puesta en peligro del consumidor.

\section{iii. Elemento Temporal}

Respecto al último elemento, el temporal, no cabe mayor explicación al respecto: La subsanación de la conducta infractora deberá realizarse de manera previa a la notificación de la imputación de cargos, y debiendo el administrado probar ello en

30 Ver artículos 28 y 29 del Código. 
el procedimiento administrativo sancionador con la finalidad de que se aplique el eximente.

A manera de ejemplo, citamos lo desarrollado por la Sala en la Resolución No. 4842019/SPC-Indecopi de fecha 22 de febrero de 2019:

“(..)

36. Cabe indicar que, si bien la denunciada alegó que el Aviso y Libro de Reclamaciones virtual se encontraban siendo implementadas en su página web el 21 de marzo de 2018, lo cierto es que dicha implementación recién pudo se acreditada con la captura de pantalla de su página web del 24 de marzo de 2018, es decir, con posterioridad a la notificación de imputación de cargos realizada - 21 de marzo de 2018 - por lo que no corresponde declarar improcedente la denuncia según lo establecido el inciso f) del artículo $108^{\circ}$ del Código, que determina la improcedencia de la denuncia por subsanación de la conducta infractora con anterioridad a la notificación de imputación de cargos." (Énfasis agregado)

Habiendo analizado la aplicación de la subsanación voluntaria en el Indecopi, consideramos que, en términos generales, el cambio legislativo ha sido positivo, pues, queda evidenciado que los Órganos Resolutivos del Indecopi han empezado a realizar una correcta adecuación a la norma común. De la misma manera, suscribimos a Morón Urbina31 cuando señala que la finalidad de la norma ha pasado a ser la correcta adecuación de la misma, antes que la disuasión a través de la imposición de multas.

\section{Conclusiones}

Desde las modificaciones introducidas por el Decreto Legislativo 1272, la LPAG se convierte en una norma imperativa que garantiza condiciones mínimas para el desarrollo de todos los procedimientos administrativos, dejando de lado cualquier interpretación referida a que tendría un carácter supletorio. Así, La LPAG es una norma de carácter común que establece las pautas y condiciones que deben regir en todos los procedimientos administrativos en general. Estas reglas y principios comunes no podrán ser disminuidos a través de normas especiales, pues, constituyen las garantías mínimas que se le otorgan a todos los administrados. En otras palabras, la LPAG establece pautas comunes que sirven como "piso" para el desarrollo de los procedimientos administrativos sancionadores.

De acuerdo a ello, debido a la propia naturaleza de los procedimientos de protección al consumidor tramitados ante el Indecopi (procedimientos

31 MORÓN URBINA, Juan Carlos. Comentarios a la Ley del Procedimiento Administrativo General. Texto Único Ordenado de la Ley N²7444. Tomo I. Lima: Gaceta Jurídica, p. 523. 
sancionadores de oficio), los Órganos Instructivos y Resolutivos deben actuar respetando las garantías y principios establecidos en la LPAG.

En relación a la caducidad, se advierte que desde la entrada en vigencia del Decreto Legislativo 1272, ésta no ha venido siendo aplicada de la mejor manera por la Autoridad Administrativa, situación que confiamos cambie en los siguientes años. No debemos dejar de mencionar que esta garantía también favorece a los consumidores, en tanto les concede seguridad jurídica y, además, dota de eficacia a las actuaciones de la Administración.

Sobre la aplicación de la subsanación voluntaria, los pronunciamientos expedidos por los Órganos de Protección al Consumidor dan cuenta que éstos han empezado a adecuarse y adaptarse a la aplicación de la LPAG como norma común. No obstante, confiamos que en los siguientes años exista una total homologación en relación a sus pronunciamientos y las reglas y principios establecidos en la LPAG. 